\title{
Belphégor
}

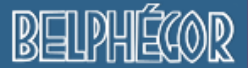

Littérature populaire et culture médiatique

18-2 | 2020

Roman Populaire Espagnol - Roman historique,

1900-1950

\section{Les conclusions des assises de la recherche "Cultures populaires et médiatiques »}

\section{Marc Lits}

\section{(2) OpenEdition}

Journals

Édition électronique

URL : http://journals.openedition.org/belphegor/3348

DOI : $10.4000 /$ belphegor.3348

ISSN : 1499-7185

Éditeur

LPCM

Référence électronique

Marc Lits, "Les conclusions des assises de la recherche "Cultures populaires et médiatiques » », Belphégor [En ligne], 18-2 | 2020, mis en ligne le 11 décembre 2020, consulté le 28 avril 2021. URL http://journals.openedition.org/belphegor/3348 ; DOI : https://doi.org/10.4000/belphegor.3348

Ce document a été généré automatiquement le 28 avril 2021.

\section{(c)}

Belphégor est mis à disposition selon les termes de la Licence Creative Commons Attribution - Pas d'Utilisation Commerciale - Pas de Modification 4.0 International. 


\title{
Les conclusions des assises de la recherche «Cultures populaires et médiatiques »
}

\author{
Marc Lits
}

Ces assises ${ }^{1}$ marquent un moment important pour les chercheurs issus de différents domaines disciplinaires qui, depuis plus de vingt ans, ont accompagné l'émergence de ces deux axes de recherche, la culture populaire et les médias, et qui suivent avec intérêt les développements récents dans ce champ de plus en plus ouvert et diversifié. Ces assises attestent en effet d'une efflorescence extrêmement riche dans un cadre toujours mouvant, tant dans ses objets étudiés que ses approches méthodologiques. C'est aussi stimulant parce que de nouvelles générations de chercheurs rejoignent les centres de recherche à l'origine de ce regroupement, en France et dans beaucoup d'autres pays. Et ces chercheurs s'inscrivent dans un cadre toujours plus large, ce dont témoigne le choix même des images présentant le programme du colloque, construites autour d'un logo explosif « POP », dans la veine des illustrations d'un Roy Lichtenstein. C'est désormais dans le contexte d'une " pop culture » revendiquée et assumée que se positionnent les nouveaux chercheurs en cultures populaires (y compris en produisant des goodies à l'image du colloque pour le faire connaître, dans une démarche promotionnelle assez semblable à celle des industries culturelles qu'ils analysent et dont ils adaptent, délibérément ou inconsciemment, les pratiques de communication). Cela a pu s'observer au long des nombreux ateliers qui se sont tenus durant trois jours, à travers quelques questionnements, souvent parallèles, parfois convergents, parfois en débat, qui peuvent être synthétisés autour de quatre entrées complémentaires : le poids des mots, le choc des supports, l'importance des enjeux, la confrontation des cadres théoriques. 


\section{Le poids des mots}

2 Quand les premières discussions autour de la création d'une association de chercheurs issus des champs de la littérature populaire et des médias de masse eurent lieu, dès 1997, à Saint-Etienne, à Limoges, au Québec, à Louvain-la-Neuve, à Saint-Quentin en Yvelines, à Cergy-Pontoise, celles-ci réunissaient des spécialistes des littératures dites populaires $^{2}$ tandis que d'autres vena ient de départements plus attachés à la communication et aux médias. L'enjeu était double : pour les chercheurs inscrits dans le champ de la littérature française ou comparée, surtout français, il y avait la volonté de faire reconnaître l'étude de ces productions populaires (livres, romans-feuilletons, livrets de colportage, presse à grand tirage...) par l'université, principalement pour les spécialistes du XIXe siècle. Pour les chercheurs en communication et médias, dont les objets majoritairement analysés étaient alors la presse écrite d'information (internet n'avait pas encore été inventé), voire les journaux télévisés dans leur contenus essentiellement politiques, le souhait de prendre en compte les productions aussi massivement diffusées qu'ignorées par ce champ disciplinaire qu'étaient la bande dessinée, les premiers feuilletons télévisés (souvent adaptés des romans-feuilletons du $\mathrm{XIX}^{\mathrm{e}}$ siècle) ou des divertissements comme le concours Eurovision de la chanson. Bref, le combat était politique, à la fois en termes de reconnaissance d'objets méprisés par l'université, pour faire accéder ces objets à des études qui devaient trouver leur place dans un champ scientifique centré sur la culture dominante et peu ouvert à reconnaître la « culture du pauvre » quand les cultural studies étaient encore ignorées en France ${ }^{3}$; et en termes d'engagement social aussi de plusieurs de ces chercheurs pour faire reconnaître la pleine valeur culturelle de ces objets méprisés et des publics qui les consommaient de manière plus critique qu'on ne le disait alors.

3 Ce combat peut sembler aujourd'hui totalement dépassé au moment où les séries télévisées apparaissent comme le nouvel objet culturel dominant de la culture contemporaine, depuis que Les Cahiers du cinéma les ont légitimées dans un numéro assez remarquét et que la sortie de la dernière saison de la série Game of Thrones fait l'objet d'analyses multiples par les sociologues, les sémioticiens, les philosophes, voire les responsables politiques. Mais il resurgit régulièrement sous d'autres formes. Charles Grivel récusait déjà le terme de littérature populaire dans son ouvrage fondateur, Production de l'intérêt romanesque ${ }^{5}$, et quand Daniel Couégnas faisait entrer la paralittérature dans le champ des études littéraires les plus valorisées par la publication de sa synthèse réflexive sur ce sous-champ dans la prestigieuse collection "Poétique» des éditions du Seuil ${ }^{6}$, le débat fut vif entre ceux qui reconnaissaient l'avancée réalisée là pour la reconnaissance de ces œuvres et ceux qui craignaient que cela ne fasse que conforter une forme d'ostracisme désormais officialisée. D'autres alors tentèrent de régler le problème en englobant ces productions paralittéraires dans le cadre plus vaste de la culture, qu'elle soit populaire ou médiatique ${ }^{7}$, mais cela ne fait sans doute que déplacer la question plutôt que de la résoudre.

Pourtant, les événements politiques et sociaux de ces dernières années, en France, aux États-Unis, dans plusieurs pays de l'Est européen montrent à suffisance que la place du populaire, et sa liaison avec le populisme, sont plus que jamais d'actualité. Au sens où Donald Trump ne serait finalement qu'un des nouveaux artefacts de la pop culture. Ces crises à répétition ne peuvent peut-être trouver des issues que dans le renforcement du rôle de la culture, de tous les types de culture, comme ciment d'une collectivité qui a 
besoin d'être réenchantée. En construisant éventuellement un nouveau modèle culturel tel que le middlebrow élaboré par les chercheurs anglophones. Il est en effet urgent, et c'est notre responsabilité de chercheur, de réinterroger les nouvelles doxas qui se construisent dans notre champ, comme l'a fait Matt Hills, et comme le montraient les échanges qui ont suivi sa conférence. Alors que le bouleversement épistémologique qui réunit notre communauté de chercheurs, et qui semble avoir gagné une bonne partie des usagers culturels, laisse à penser que la culture dominante est aujourd'hui la culture populaire, il est nécessaire de se réinterroger sur les questions premières des superstructures, des agents économiques et du contrôle de l'hégémonie culturelle. Si c'est la culture mainstream qui est désormais hégémonique, tant sur le plan commercial qu'esthétique, si les débats qui avaient agité les chercheurs lors de la sortie du livre de Daniel Couégnas en 1992 n'ont plus lieu d'être vingt-cinq ans plus tard quand Matthieu Letourneux sort un essai sur les mêmes objets dans la même collection ${ }^{8}$, si les sociologues se sont approprié les avancées critiques des chercheurs de la LPCM en popularisant le concept de "médiaculture", si l'emprise distinctive de Pierre Bourdieu sur une approche culturelle des productions de masse est moins prégnante qu'avant, on ne peut pour autant baisser la garde et oublier toute distance critique par rapport à nos modèles épistémologiques explicites et implicites. Si les réflexions d'un Walter Benjamin sur l'aura de l'œuvre créatrice ne sont plus pertinentes pour expliquer les qualités d'une série télévisée ou d'une bande dessinée, on ne peut ignorer les enjeux économiques, politiques, esthétiques, culturels qui conditionnent ces productions, ni les valeurs qu'elles véhiculent, pour autant que ce dernier terme soit encore audible à l'heure de la fan culture.

\section{Le choc des supports}

5 Ce qui a le plus fait exploser le champ des productions culturelles de masse, c'est tout d'abord la diversification des supports et leur démultiplication grâce à une baisse des prix rendue possible par les évolutions techniques des conditions de production et les tirages croissant en parallèle avec le développement de l'instruction de masse depuis la fin du XIXe siècle. Cette culture populaire ou médiatique s'inscrit donc dans l'horizon européen dès la fin de la première moitié du XIX siècle, si l'on suit les hypothèses de Marie-Eve Thérenty et Alain Vaillant ${ }^{10}$. Depuis lors, les nouveaux supports se sont développés de manière exponentielle, dans des formats de plus en plus variés et hybrides : le cinéma, la radio, la télévision, la bande dessinée pour ne citer que les plus anciens, aujourd'hui légitimés au point d'être entrés dans les musées et les salles de vente. Si l'on regarde les supports et objets analysés au long des exposés de ce colloque et dans les débats, on y trouve aussi les web docus, les mooks, les fan fictions, les jeux vidéo, les jeux en ligne, la tweetlittérature, les live tweet, les instagram stories, les images et récits publiés sur Snapshat ou Facebook, les séries pour smatphones, les graphic novels, les productions des Youtubers, et j'en oublie.

6 Tous ces lieux, ces supports, ces textes, ces images évoluent en permanence et s'entremêlent sans cesse, selon le modèle bien décrit par Henry Jenkins ${ }^{11}$, entraînant de nouveaux enjeux pour l'analyse des cultures médiatiques (pour lesquelles la qualification de populaire semble avoir définitivement disparu).

7 Les enjeux que cela soulève sont de trois ordres: la part croissante de l'hybridation dans les objets transmédiatiques; la transformation des temporalités, tant des 
productions que des consommations, liée aux effets de la sérialité ; la place plus grande laissée aux usagers dans des logiques de participation et d'interaction.

\section{Hybridations transmédiatiques}

8 La culture médiatique croise depuis longtemps des formes et des supports hybrides, comme l'a montré Charles Grivel dans son analyse des ciné-romans du début du XX siècle ${ }^{12}$, et comme l'a finement démontré Jan Baetens avec le succès croissant, quoique discrètement occulté par les éditeurs, des novellisations ${ }^{13}$. Les objets de la culture de masse sont dorénavant transmédiatiques, transmédiagéniques, multimédia et se consomment dans des offres crossmedia. Les études portent dès lors parfois davantage sur les supports qui accueillent ces histoires que sur leur contenu, y compris à travers la recension analytique des objets dérivés dont les industries culturelles sont friandes pour relancer l'intérêt (et la pulsion d'achat) de l'usager devenu un consommateur fan. Cela modifie donc les modalités de l'analyse de ces produits, mais aussi de notions qui se sont radicalement transformées comme celle d'auteur ou de créateur. On connaissait déjà l'auctorialité binaire des productions en bande dessinée co-réalisées par un scénariste et un dessinateur (en oubliant les équipes de coloristes ou rédacteurs typographiques des phylactères déjà présents dans les studios d'Hergé et chez Dupuis), on doit désormais identifier la part de travail des auteurs de jeux vidéos, des novellisations, voire des fan fictions générées par les succès des Harry Potter et autres séries à succès. Où est l'auteur dans ce dernier exemple, quelle est la distinction entre l'auteur et le lecteur, en quoi cela modifie-t-il et le travail créatif de l'auteur et la posture de l'usager lecteur? Comment prendre en compte la totalité de ces gigarécits qui occupent l'espace infini du net, là où on pouvait auparavant travailler l'œuvre complète d'un auteur unique (du moins une fois qu'il était décédé). Et cette question de l'hybridité des supports doit être prise en compte en parallèle avec l'hybridation transgénérique, telle qu'elle avait déjà été discutée dans un colloque à Limoges en avril $2003^{14}$

\section{Temporalité et sérialité}

9 La figure de l'auteur unique est remise en question, tout comme le modèle de l'œuvre unique, close sur elle-même, limitée par un incipit d'ouverture (même si l'on a glosé sur la place de la couverture dans le dispositif d'activation de la lecture, ou des épigraphes placées en préambule, dans la lignée des recherches de Gérard Genette sur l'architexte ${ }^{15}$ ) et un excipit qui met un terme au récit ( «I'm a poor lonesome cowboy »...). Le récit est d'emblée conçu pour s'inscrire dans un ensemble d'épisodes, comme ce fut immédiatement le cas pour les fictions télévisuelles, mais comme cela se décline aussi aujourd'hui en cinéma. Le projet de Star Trek fut le modèle de ces conceptions sérielles, qui se prolongent même en prequel ou sequel, dans la logique de Star Wars, et dans d'innombrables successions, nécessitées pour satisfaire les amateurs de binge watching, puisque la vision à la demande est techniquement organisée pour fournir des épisodes en grande quantité. Certes, cela existait déjà depuis les romansfeuilletons du XIXe siècle, où les épisodes se succédaient pour fidéliser l'acheteur du journal au jour le jour, et où le succès des Mystères de Paris a donné lieu à une efflorescence de Mystères urbains dans de nombreux pays et continents ${ }^{16}$. Et ces 
histoires à rallonge circulaient aussi sur différents supports, à l'écran, en récits imagés, en fascicules pour le colportage, en cartes à jouer (ancêtres des produits dérivés actuels). Mais la sérialité est aujourd'hui la norme, dans la production comme dans les logiques de consommation, en direct ou en différé continu. Cela a des impacts sur les cadres théoriques nécessaires pour comprendre ces nouveaux objets de la culture de masse, ou plus exactement ces nouvelles offres culturelles.

\section{Participation et interaction}

Si l'offre a changé, c'est surtout sa consommation qui connaît des transformations radicales. Même si on évoquait déjà des formes de rétroaction dans les premières théories de la communication, on a basculé désormais d'un modèle classique unidirectionnel Emetteur / Message / Récepteur vers un modèle co-construit de manière interactionnelle. Si on prend le cadre ricœurien, tel qu'il le développe dans son étude Temps et récit ${ }^{17}$, on est passé définitivement du primat de la mimesis II (la mise en forme du récit est organisée par l'écrivain ou le journaliste) à la mimesis III, dans la mesure où c'est dans la phase d'appropriation du récit par son récepteur que se construit définitivement ce récit, dans des mouvements d'aller et retour vers l'émetteur et les autres récepteurs qui interagissent en parallèle et en simultanéité. C'est ce qu'évoque d'ailleurs Raphaël Baroni dans son exposé «Pour une narratologie transmédiale $»^{18}$.

11 Il n'est dès lors pas surprenant que de nombreuses communications de ce colloque s'intéressent aux usages plus qu'aux contenus : observation des sites de fan fiction ou des joueurs de jeux vidéo en ligne, voire suivi des sites de commentaires de ces sites et jeux, à travers les blogs et comptes twitter des participants, qui interviennent ainsi à un méta-niveau dans la construction de ces récits en ligne. Auparavant, l'analyse de la réception se réalisait a posteriori, via des questionnaires posés après l'acte de consommation du média (pensons à l'enquête célèbre d'Elihu Katz sur la réception mondiale de Dallas ${ }^{19}$ ), ce qui entrainait nombre de biais; désormais, elle s'effectue au moment même où interagissent les émetteurs et les récepteurs (mais ces termes euxmêmes sont périmés) en live-tweet, sue Facebook live. Mais d'autres biais apparaissent, qu'il faudra rapidement identifier, au moment où les big data deviennent un outil indispensable dans l'analyse de ces données et méta-données, qu'on maîtrise encore assez mal dans le secteur des sciences humaines et sociales.

Il ne faut pas non plus être dupe dans la surévaluation de ces transformations des pratiques de consommation multimédia. Il y a toujours des auteurs et des créateurs à la source de ces récits, même s'ils sont regroupés dans des studios de scénaristes, et qu'ils sont devenus des salariés au service d'un projet éditorial porté par une entreprise du divertissement. La valorisation construite de ce modèle pseudo-participatif par les industries culturelles repose souvent sur des enjeux de type économique. Il y aurait donc une certaine naïveté à survaloriser ces processus participatifs et à entonner le refrain du "tous créateurs, tous co-créateurs". 


\section{La confrontation des cadres théoriques}

13 Cette transformation des usages entraine une nécessaire diversification des cadres théoriques et méthodologiques et sans doute aussi une révision de ces mêmes cadres.

\section{La diversité des approches}

14 A la diversité des supports et des usages répond une diversité des analyses et des approches. Celle-ci est indispensable, mais entraîne deux risques. Comment est-il encore possible de tout appréhender dans cette explosion de l'offre et cet éclatement de la consommation? Comment éviter la dispersion des courants d'analyse, des niches interprétatives, démultipliées par les types d'objets pris en compte (au point que certains créent leur propre sous-champ disciplinaire comme les game studies) et les références scientifiques convoquées? De nombreux ateliers étaient proposés dans ce colloque, organisés autour des termes "Réceptions, Circulations, Récits, Productions, Cultures", termes génériques tous mis au pluriel, ce qui est à la fois justifié et interpellant. Tous ces ateliers étaient également importants, nécessaires, interconnectés. On y retrouvait des narratologues et des sémiologues, des sociologues (qui avaient longtemps, en France comme dans d'autres pays européens, ignoré les médias de masse avant de revenir en force dans le champ), des anthropologues qui s'intéressent au terrain des jeux vidéos mais entrent aussi dans l'analyse des mondes virtuels eux-mêmes, des économistes (mais en nombre encore limité), des chercheurs en communication et journalisme (sur les mooks ou les webdocus), des ingénieurs en télécommunication (peu ont fait le saut des tuyauteries aux contenus, mais ils sont essentiels pour comprendre ce qui se passe dans la réalité virtuelle ou augmentée), des historiens (pour revenir sur les cadres socio-culturels et inscrire tous ces phénomènes dans la longue durée des usages), des psychologues spécialisés en psychologie sociale ou dans le champ des émotions, des juristes utiles pour comprendre le droit des médias et de la communication, des politistes pour analyser les séries télévisées comme $24 \mathrm{~h}$ chrono ou The West Wing, des spécialistes des études cinématographiques (pour le cross media entre autres), de la littérature, des littératures comparées, de l'esthétique, des arts (appliqués ou non).

15 Cet inventaire à la Prévert (ou plutôt à la Borges, tel que Michel Foucault le commente dans la préface de son essai Les mots et les choses ${ }^{20}$ ) montre la richesse des cadres possibles, pour analyser ces phénomènes trans- ou cross-media, à l'aide de théories elles-mêmes devenues trans- ou cross-théories. C'est une question devenue également centrale dans les sciences de l'information et de la communication ${ }^{21}$. Comment peut-on rassembler et faire dialoguer des chercheurs issus d'autant de domaines différents dans une même équipe de recherche, qui doivent se partager des concepts et des méthodes issus de champs disciplinaires parfois très opposés. C'est cependant nécessaire, si l'on regarde l'exemple de l'analyse du storytelling popularisée par Christian Salmon ${ }^{22}$. Cette approche sociologique a apporté un éclairage nécessaire et pertinent sur ces nouveaux modes d'écriture, en en dénonçant les dérives et les aspects manipulatoires, mais sans inscrire cette analyse dans une histoire narratologique qui aurait pu davantage la mettre en perspective et éviter certains jugements idéologiques à nuancer ${ }^{23}$. Un autre risque réside dans l'éclatement de cadres théoriques trop pris par le prisme de l'objet analysé, ou par le primat donné à une entrée spécifique. Cela se marque alors dans le 
développement de nouveaux champs disciplinaires, comme déjà évoqué pour les game studies, mais qui transparaît aussi dans l'émergence des visual studies, ou l'éclatement des cultural studies en gender studies, american studies, queer studies et autres microapproches dédiées à un seul type de support ou de public. Quel équilibre dès lors trouver entre approches micro, méso ou macro, entre focalisation excessive sur un cas particulier et compréhension d'enjeux plus globaux, qu'ils soient sociaux ou internes aux systèmes de production ou de réception?

\section{Une transformation des approches}

16 Si l'on prend l'exemple de la narratologie, terrain qui m'est le plus familier, on peut observer la manière dont ces nouveaux produits transmédiatiques modifient les pratiques rédactionnelles. La dimension sérielle amène désormais à construire autrement un personnage, à le faire progresser au fil d'histoires qui vont se décliner en plusieurs années, sur une période longue. A imaginer aussi des héros multiples là où le romancier privilégiait la confrontation entre un nombre restreint d'acteurs. Cela oblige à redéfinir les cadres théoriques définissant les traits du personnage, depuis que les modèles structuralistes s'y sont appliqués. L'approche d'un Philippe Hamon, au départ de l'analyse des Rougon-Macquart ${ }^{24}$ (qui est pourtant une fresque à multiples personnages se déroulant sur un temps assez long) ne peut sans doute plus s'appliquer telle quelle aux multiples productions hébergées sous les marques Star Trek ou Star Wars.

17 Il en va de même pour la construction du récit. J'avais suggéré, il y a quelques années, de passer d'une narratologie classique à une hypernarratologie ${ }^{25}$ (à l'époque on parlait encore d'hypertexte mais ce terme semble aujourd'hui périmé) dans la suite de ce que Jan Baetens développait autour du concept d'hyperfiction dans un colloque de la $\mathrm{LPCM}^{26}$. Le passage de la mimesis II à la mimesis III comme cœur de la construction narrative, pour mieux intégrer la réception des usagers dans un phénomène de construction partagée donne lieu à un nouveau temps dans l'histoire de la narratologie, à une post-narratologie comme l'avance Raphaël Baroni. Il y a plus de vingt-cinq ans, Gérard Genette suggérait déjà d'élargir au «récit factuel» les méthodes de la «narratologie fictionnelle» par une "vaste enquête à travers des pratiques comme l'Histoire, la biographie, le journal intime, le potin quotidien ${ }^{27}$ (...)», ce que la narratologie classique n'était pas prête à entendre. Aujourd'hui, cette prise en compte de la diversité des récits fictionnels et issus de la réalité (la frontière étant de plus en plus poreuse entre réel, fictionnel et virtuel) est naturelle pour les post-narratologues. L'évolution des objets que nous prenons en compte fait aussi bouger les cadres de référence, et la notion de "récit médiatique " n'est plus du tout perçue comme oxymorique $^{28}$. Les délocalisations théoriques et méthodologiques, imposées par la transformation des objets et pratiques analysés, obligent les chercheurs à une grande inventivité, très productive, dans les recherches en littérature, en histoire, en sociologie et anthropologie, en sciences politiques (même si $24 \mathrm{~h}$ chrono n'a pas fait élire Barack Obama comme certains l'avanceraient un peu rapidement), en économie...

18 La relation entre facts et fiction (que les chercheurs anglophones contractent parfois en un seul terme : faction) a aussi évolué, avec davantage de transgression ou de fluidité entre ces types de produits, selon l'angle que l'on veut privilégier. Plusieurs des communications du colloque ont porté sur ces jeux entre le réel et l'imaginaire, sur la 
réalité virtuelle (syntagme qui contient bien ces deux axes trop vite opposés), sur la suspension of disbelief dans nos consommations fictionnelles.

Et bien d'autres questions peuvent encore être soulevées: les valeurs critiques et esthétiques de ces nouveaux objets, leur place et leur reconnaissance dans le système scolaire, leur rôle dans la reconnaissance des minorités sociales, culturelles, genrées. La question aussi des corpus à constituer et de la difficulté à les délimiter, voire à les saisir en cas d'inflation des données et métadonnées. Ou la question de l'hybridation des genres, des pactes ou contrats de lecture. Autant de questions ouvertes soulevées par ces nouveaux objets de la culture médiatique.

\section{En guise d'ouverture}

Ce bouillonnement d'idées, de concepts, ce foisonnement d'objets, de méthodes ont fait la richesse d'un colloque passionnant, où les questions ont été plus nombreuses que les réponses, dans un nombre de panels extrêmement diversifiés, y compris avec des approches anglophones et internationales qui apportent de nouveaux éclairages aux chercheurs issus de la francophonie. Il est aussi réjouissant d'y croiser des jeunes chercheuses et chercheurs totalement immergées dans des objets et pratiques culturels de leur génération (mais en n'oubliant pas les nécessaires mises en perspective et en contexte). On a trop longtemps oublié que le cinéma ne venait pas de nulle part, qu'il n'y a pas eu à la projection des premiers courts métrages des frères Lumière une sorte de saut quantique médiatique, puisque les historiens de la culture et du cinéma ont bien montré que cette invention s'inscrivait dans la tradition des lanternes magiques animées que les colporteurs montraient depuis longtemps dans les villages. Ce bouillonnement actuel, s'il veut se construire dans une rigueur scientifique indispensable, doit s'inscrire dans la longue durée de l'histoire culturelle des médias. Il a un passé, mais il a aussi un avenir dont nous n'avons sans doute encore saisi que les premiers balbutiements. Et les prochaines Assises, dans cinq ans, dans dix ans, dans vingt ans, serviront à montrer combien nous fûmes, ici et maintenant, ou des ouvreurs de champs nouveaux, ou des aveugles errant sans rien comprendre à ce qui commençait à s'inventer.

\section{NOTES}

1. Ce texte reprend dans une version remaniée le discours de clôture des «Assises de la recherche en cultures populaires et médiatiques » qui se sont tenues du 11 au 13 octobre 2018 à Paris Nanterre et à Paris 3.

2. Le principe de l'analyse de ces mauvais genres avait commencé à être répandu par les Actes d'un colloque fameux à Cerisy-la-Salle, « Littérature et paralittérature », dirigé par Noël Arnaud, Francis Lacassin et Jean Tortel, du 1er au 11 septembre 1967 et publié sous le titre Entretiens sur la paralittérature par la Librairie Plon en 1970 (réédité en 2012 par Hermann Editeurs). 
3. Cf. «Peuple, populaire, populisme », dossier coordonné par Pascal Durand et Marc Lits, Hermès, $\mathrm{n}^{\circ} 42$, 2005, et particulièrement les articles de Dominique Pasquier, «La "culture populaire" à l'épreuve des débats sociologiques » et de Jan Baetens, «La culture populaire n'existe pas, ou les ambiguïtés des cultural studies ».

4. Les Cahiers du cinéma, « L'âge d'or de la série américaine ", juillet-août 2003.

5. Charles Grivel, Production de l'intérêt romanesque. Un état du texte (1870-1880), un essai de constitution de sa théorie, La Haye-Paris, Mouton, 1973. Disponible en ligne à l'adresse https:// dalspace.library.dal.ca/bitstream/handle/10222/47786/09_02_Grivel_prod_cont.pdf? sequence $=1 \&$ isAllowed $=\mathrm{y}$

6. Daniel Couégnas, Introduction à la paralittérature, Paris, Ed. du Seuil, coll. "Poétique", 1992.

7. Marc Lits, «De la culture populaire à la culture médiatique. Marchandisation et mondialisation ", Recherches sociologiques, 2005, vol. 2-3, pp. 77-98.

8. Matthieu Letourneux, Fictions à la chaîne. Littératures sérielles et culture médiatique, Paris, Ed. du Seuil, coll. "Poétique", 2017.

9. Eric Macé et Eric Maigret, Penser les médiacultures, Paris, Armand Colin/INA, 2005.

10. Marie-Ève Thérenty et Alain Vaillant, 1836, l'an 1 de l'ère médiatique, Paris, Nouveau Monde Editions, 2001.

11. Henry Jenkins, La culture de la convergence. Des médias au transmédia, Paris, A. Colin/INA, coll. "Médiacultures", 2013.

12. In Jan Baetens et Marc Lits (eds), La novellisation/Novelization. Du film au livre. From film to novel, Leuven, Leuven University Press, coll. "Symbolae - Series D Literaria”, vol. 17, 2004.

13. Jan Baetens, La novellisation. Du film au roman, Bruxelles, Les Impressions nouvelles, 2008.

14. Cf. Belphégor, « Le genre et la culture de masse », vol. 3, n 1, décembre 2003.

15. Gérard Genette, Introduction à l'architexte, Paris, Ed. du Seuil, coll. "Poétique”, 1979.

16. Marie-Eve Thérenty (dir.), Les mystères urbains au prisme de l'identité nationale, Médias 19, 2013, https://lpcm.hypotheses.org/7376; Dominique Kalifa et Marie-Eve Thérenty (dir.), Les mystères urbains au XIX siècle: circulations, transferts, appropriations, Médias 19, 2015, http:// www.medias19.org/index.php?id=17039.

17. Paul Ricœur, Temps et récit, 3 vol., Paris, Ed. du Seuil, 1983-1985.

18. Raphaël Baroni, "Pour une narratologie transmédiale ", Poétique, 2017, 2, 182.

19. Elihu Katz et Tamar Liebes, The Export of Meaning, Cross Cultural Reading of Dallas, New York, Oxford University Press, 1990. CF. également Ien Ang, Watching Dallas, London, Methuen, 1985.

20. Michel Foucault, Les mots et les choses, Paris, Gallimard, 1966. Il y reprend un apologue de Jorge-Luis Borges publié dans "La langue analytique de John Wilkins", in Enquêtes, Paris Gallimard, 1957.

21. Cf. Patrick Charaudeau, «Pour une interdisciplinarité "focalisée" dans les sciences humaines et sociales ", Questions de Communication, 2010/1, n 17, pp. 195-222.

22. Christian Salmon, Storytelling, la machine à fabriquer des histoires et à formater les esprits, Paris, La Découverte, 2007.

23. Cf. Marc Lits, "Storytelling, réévaluation d'un succès éditorial », in Nicolas Pélissier et Marc Marti, Le storytelling. Succès des histoires, histoire d'un succès, Paris, L'Harmattan, coll. "Communication et civilisation", 2012, pp. 23-38.

24. Philippe Hamon, "Pour un statut sémiologique du personnage ", Littérature, 1972, réédité dans Poétique du récit, Paris, Ed. du Seuil, 1977) ; Le personnel du roman, Genève, Droz, 1983, réédité en 1998.

25. Marc Lits, «Quel futur pour le récit médiatique?", Questions de communication, $\mathrm{n}^{\circ} 21,2012$, pp. 37-48.

26. Jan Baetens, "Hyperfiction et théorie des médias", in La culture médiatique aux XIXe et XXe siècles. Actes du colloque de Louvain-la-Neuve de juin 1999, Louvain-la-Neuve, «Les Dossiers de l'ORM », n 6, novembre 1999, pp. 17-24. 
27. Gérard Genette, Fiction et diction, Paris, Ed. du Seuil, coll. "Poétique", 1991, p. 67.

28. Marc Lits, «Le récit médiatique: un oxymore programmatique?», Recherches en communication, $\mathrm{n}^{\circ} 7,1997$, pp. 37-59.

\section{AUTEUR}

\section{MARC LITS}

Observatoire des recherches sur les médias et le journalisme (ORM)

Université catholique de Louvain 